\title{
La herida social del paciente dependiente
}

Los cambios sociales, junto a los avances tecnológicos y farmacológicos de las últimas décadas, han dado lugar a un aumento de la esperanza de vida que ha acarreado un aumento igualmente notable y significativo de la dependencia. Como consecuencia de esto la demanda de cuidados se ha incrementado, y se espera que siga haciéndolo a un fuerte ritmo durante los próximos años.

Antes de abordar la situación actual de la dependencia en nuestro país, debemos definir unos conceptos que se desarrollan en la Ley 39/2006, de 14 de diciembre, de Promoción de la Autonomía Personal y Atención a las personas en situación de dependencia.

En primer lugar, el concepto de autonomía:

"La capacidad de controlar, afrontar y tomar, por propia iniciativa, decisiones personales acerca de cómo vivir de acuerdo con las normas y preferencias propias, así como de desarrollar las actividades básicas de la vida diaria" (1).

$\mathrm{Y}$, en segundo lugar, el concepto de dependencia:

"Estado de carácter permanente en que se encuentran las personas que, por razones derivadas de la edad, la enfermedad o la discapacidad, y ligadas a la falta o a la pérdida de autonomía física, mental, intelectual o sensorial, precisan de la atención de otra u otras personas o ayudas importantes para realizar actividades básicas de la vida diaria o, en el caso de las personas con discapacidad intelectual o enfermedad mental, de otros apoyos para su autonomía personal" (1).

Resulta muy llamativo que, en la definición de estos dos términos, encontremos un tercer concepto, "actividades básicas de la vida diaria", que forma parte del lenguaje que las enfermeras utilizan durante su práctica profesional habitual y que denota una sensibilidad que entronca esta ley directamente con la idiosincrasia enfermera. Cabe pensar que, en el momento de su redacción, los legisladores eran conscientes de que cuando las personas o familias están en una situación de dependencia o de riesgo de dependencia, las enfermeras son, sin duda, los profesionales mejor capacitados para valorar qué necesidades básicas están comprometidas y para planificar los cuidados necesarios.

Con respecto a la situación de la dependencia en España en la actualidad, a fecha del 31 de Agosto de 2019, hay 1.093.620 personas beneficiarias con prestación a través del sistema para la autonomía y la atención a la dependencia del Instituto de Mayores y Servicios Sociales (Imserso), de los cuales el 72,45\% tiene 65 años o más, y el 54,4\% tiene más de 80 años (2). Este dato se contextualiza mejor destacando que la mayoría de los cuidados a estas personas dependientes proviene del seno familiar, recayendo la responsabilidad mayormente en la mujer (Cuesta 2009 y Ruiz Robledillo). Se calcula que, ya en el año 2008, se dedicaron 4600 millones de horas al cuidado de personas dependientes, lo que supone un $5 \%$ del PIB de ese mismo año (3-6).

Estos datos arrojan una realidad que no debe ser obviada por los colectivos enfermeros, ya que somos los profesionales encargados de la planificación y seguimiento de los casos en los países donde mejor se han desarrollado las políticas sociales. Las personas dependientes en España deben tener una legislación que los ampare y que sea desarrollada, ejecutada y apoyada por la implantación de recursos humanos y materiales.

La "herida social" del paciente dependiente, al igual que una herida compleja, precisa de un tratamiento específico, de unos cuidados planificados, de un equipo multidisciplinar y de una evaluación periódica.

Afrontar el problema de la atención a las personas en situación de dependencia es una responsabilidad ineludible de los agentes sociales y políticos, pero es también una oportunidad que las enfermeras debemos aprovechar: los datos son arrolladores y, las enfermeras, como agentes de cambio, tenemos el deber de detectar y derivar a los pacientes dependientes que atendemos y que, en muchos casos, no han iniciado los trámites para que sea reconocida su situación. Así mismo, debemos orientar, cuidar y atender a las cuidadoras informales (son en su mayoría mujeres) que precisen ayuda y puedan beneficiarse de la integración en programas específicos de cuidados al cuidador. Por último, debemos investigar en este campo para ayudar a visibilizar una realidad que, solo de esa manera, recibirá la atención que merece por parte de los diferentes responsables políticos, tanto en el ámbito de las comunidades autónomas como a nivel estatal.

\section{Bibliografía}

1. Ley 39/2006, de 14 de diciembre, de Promoción de la Autonomía Personal y Atención a las personas en situación de dependencia. (núm. 299, de 15 de diciembre de 2006)

2. Instituto de Mayores y Servicios Sociales [Internet]. 2015. Información destacada de la evolución de la gestión del SAAD. Disponible en:

http://www.imserso.es/imserso_01/documentacion/estadisticas/info_d/estadisticas/est_inf/otros_inf/id/index.htm 
3. Oliva J, Vilaplana C, Osuna R. El valor social de los cuidados informales provistos a personas mayores en situación de dependencia en España. Gac Sanit. 2011;25(SUPPL. 2):108-14.

4. Jorgensen N, Cabañas M, Oliva J, Rejas J, León T. Los costes de los cuidados informales asociados a enfermedades neurológicas discapacitantes de alta prevalencia en España. Neurologia. 2008;23(1):29-39.

5. Ruiz-Robledillo N, Moya-Albiol L. El cuidado informal: una visión actual. Rev Motiv y emoción. 2012; 1:22-30.

6. Salazar Agulló Modesta. Las enfermeras y la Ley de Dependencia en España. Index Enferm [Internet]. 2006; 15(5253): 07-09. Disponible en:

http://scielo.isciii.es/scielo.php?script=sci_arttext\&pid=S1132 12962006000100001\&lng=es.

Pedro Raúl Castellano Santana Hospital Universitario Insular de Gran Canaria 